\title{
Clinicopathological features and CCT2 and PDIA2 expression in gallbladder squamous/ adenosquamous carcinoma and gallbladder adenocarcinoma
}

Qiong Zou ${ }^{1,2}$, Zhu-lin Yang ${ }^{2^{*}}$, Yuan Yuan ${ }^{1,2}$, Jing-he Li ${ }^{3}$, Lu-feng Liang ${ }^{4}$, Gui-xiang Zeng ${ }^{5}$ and Sen-lin Chen ${ }^{6}$

\begin{abstract}
Background: Gallbladder cancer (GBC) is a relatively uncommon carcinoma among gastrointestinal cancers and usually has a rather poor prognosis. The most common subtype of GBC is adenocarcinoma (AC), which accounts for about $90 \%$ of GBC. Squamous carcinoma/adenosquamous carcinoma (SC/ASC) are comparatively rare histopathological subtypes of GBC. The clinicopathological features and biological behaviors of SC/ASC have not been well-characterized. No molecular biomarkers are currently available for predicting the progression, metastasis, and prognosis of the SC/ASC subtype of GBC.
\end{abstract}

Methods: We examined the expression levels of CCT2 and PDIA3 by immunohistochemistry (IHC) staining in human GBC tissue samples collected from 46 patients with SC/ASC and evaluated the clinicopathological significance of both CCT2 and PDIA3 expression in the SC/ASC subtypes of GBC by Kaplan-Meier analysis and multivariate Cox regression analysis. For comparison, we included specimens from 80 AC patients in our study to investigate the specificity of CCT2 and PDIA3 expression in GBC subtypes.

Results: We found that the positive expression of CCT2 and PDIA3 was significantly associated with clinicopathological features of both SC/ASC and AC specimens, including high TNM stage and lymph node metastasis. Univariate analysis revealed that the two-year survival rate was significantly lower for patients with positive expression of CCT2 and PDIA3 than for those with negative expression. Multivariate analysis also indicated that the positive expression of CCT2 and PDIA3 was negatively correlated with poor postoperative patient survival and positively correlated with high mortality.

Conclusions: Our study suggests that positive expression of CCT2 or PDIA3 is associated with tumor progression and the clinical behavior of gallbladder carcinoma. Therefore, CCT2 and PDIA3 could be potentially important diagnostic and prognostic biomarkers for both SC/ASC and AC subtypes of GBC.

Keywords: gallbladder cancer, adenocarcinoma, squamous cell carcinoma, adenosquamous carcinoma, CCT2, PDIA3

\section{Background}

Gallbladder cancer (GBC) is a relatively uncommon gastrointestinal carcinoma, but its incidence is increasing worldwide and its prognosis is rather poor [1]. Early diagnosis and radical resection, when possible, are helpful in improving prognosis. However, it is usually

\footnotetext{
*Correspondence: zhulinyang2013@163.com

${ }^{2}$ Research Laboratory of Hepatobiliary Diseases, Second Xiangya Hospital, Central South University, Changsha, Hunan 410011, PR China

Full list of author information is available at the end of the article
}

impossible to diagnose $\mathrm{GBC}$ at its early stages due to the lack of obvious and specific symptoms. Common symptoms do not develop until GBC is at an advanced stage and include steady pain and discomfort in the upper right abdomen. Clinically, over 90\% of GBC patients are diagnosed at an advanced stage when the outcome of surgical therapy is very poor. Most patients die within one year after diagnosis [2]. The majority of $\mathrm{GBC}$ is adenocarcinoma (AC), accounting for about $90 \%$ of $\mathrm{GBC}$, while the squamous cell carcinoma/

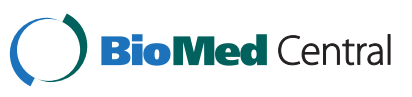


adenosquamous carcinoma (SC/ASC) are very uncommon and only account for $1.4 \%$ to $10.4 \%$ of GBC [1]. Because of the low incidence of SC/ASC, their clinicopathological features and biological behaviors have not been well characterized. Most previous reports focus on patient summaries or survival analyses [3-8]. To date, no molecular biomarkers are available for SC/ASC to predict their progression, metastasis, and prognosis.

CCT2 (chaperonin containing TCP1, subunit 2) is a molecular chaperone, a subunit of the TCP1 complex, which helps the correct folding of many proteins such as actin and tubulin which are important in maintaining the dynamic equilibrium of cell stability [9-15]. The overexpression of CCT2 is highly related to the tumorigenesis, tumor progression, and prognosis of some cancers, including hepatocellular carcinoma and colonic carcinoma [16-18]. In addition, the expression of CCT2 is significantly higher in gastric carcinoma than in normal gastric mucosa [19]. Increased expression of CCT2 also contributes to tumor cell resistance to chemotherapy and radiation therapy [20].

PDIA3 (protein disulfide isomerase A3) is a member of the disulfide isomerase family proteins [21,22] and is a component of the molecular chaperone complex containing calnexin and calreticulin, which promotes the correct folding of newly synthesized glycoproteins in the endoplasmic reticulum [21,22]. In the endoplasmic reticulum, PDIA3 facilitates the formation of disulfide bonds in glycoproteins through its redox isomerase activity. The expression level of PDIA3 in cancer cells is linked to tumor progression and prognosis of some human tumors. For example, PDIA3 expression is increased in ovarian cancer cells and has been considered as a potential biomarker for ovarian cancer prognosis [23]. PDIA3 expression in hepatocellular carcinoma is positively correlated with tumor grade and alpha-fetoprotein (AFP) level [24]. Down-regulation of PDIA3 by siRNA can inhibit the proliferation of breast cancer cells [25]. In addition, PDIA3 expression in cancer cells is critical for tumor cell resistance to thermotherapy in A549 and UO31 cancer cell lines [26]. Therefore, the high level of PDIA3 expression is an important potential biomarker for rapid tumor progression and poor prognosis.

Although their clinical importance was well studied in other cancers, the expression of CCT2 and PDIA3 and their clinicopathological significance in gallbladder cancer have never been investigated. In this study, we determined the expression levels of CCT2 and PDIA3 by immunohistochemistry staining in tumor samples from $46 \mathrm{SC} / \mathrm{ASC}$ and $80 \mathrm{AC}$ patients, and then investigated the relationship between these expression levels and tumor progression as well as the prognosis.

\section{Methods}

\section{Patients}

We collected data and tumor specimens from 46 patients diagnosed with gallbladder SC/ASC (26 SC patients and 20 ASC patients) who were surgically treated in seven local hospitals between January 1995 and December 2009. These patients accounted for $4.34 \%(46 / 1,060)$ of all cases of

Table 1 The CCT2 and PDIA3 expression and clinicopathological features of gallbladder SC/ASC and AC

\begin{tabular}{|c|c|c|c|c|}
\hline $\begin{array}{c}\text { Clinicalpathological } \\
\text { features }\end{array}$ & $\begin{array}{l}\text { SC/ASC } \\
(n=46)\end{array}$ & $\begin{array}{c}A C \\
(n=80)\end{array}$ & $\chi^{2}$ & $P$ \\
\hline \multicolumn{5}{|l|}{ Gender } \\
\hline male & 19(41.3) & $26(32.5)$ & 0.986 & 0.352 \\
\hline female & $27(58.7)$ & $54(67.5)$ & & \\
\hline \multicolumn{5}{|l|}{ Age (years) } \\
\hline$\leq 45$ & $3(6.5)$ & $16(20.0)$ & 4.143 & 0.042 \\
\hline$>45$ & $43(93.5)$ & $64(80.0)$ & & \\
\hline \multicolumn{5}{|l|}{ Degree of differentiation } \\
\hline well-differentiated & $16(34.8)$ & $27(33.8)$ & 8.515 & 0.014 \\
\hline moderately-Differentiated & $24(52.2)$ & $25(31.3)$ & & \\
\hline poorly-differentiated & $6(13.0)$ & $28(35.0)$ & & \\
\hline
\end{tabular}

Tumor maximum diameter

$(\mathrm{cm})$

\begin{tabular}{|c|c|c|c|}
\hline$\leq 3 \mathrm{~cm}$ & $20(43.5)$ & $50(62.5)$ & $4.280 \quad 0.039$ \\
\hline$>3 \mathrm{~cm}$ & $26(56.5)$ & $30(37.5)$ & \\
\hline
\end{tabular}

Gallbladder stones

\begin{tabular}{|c|c|c|c|c|}
\hline no & $18(39.1)$ & $42(52.5)$ & \multirow[t]{2}{*}{2.093} & 0.148 \\
\hline yes & $28(60.9)$ & $38(47.5)$ & & \\
\hline \multicolumn{5}{|c|}{ TNM stage } \\
\hline $1+\|$ & $12(26.1)$ & $21(26.3)$ & \multirow[t]{3}{*}{0.287} & \multirow[t]{3}{*}{0.866} \\
\hline III & $20(33.5)$ & $38(47.5)$ & & \\
\hline IV & $14(30.4)$ & $21(26.3)$ & & \\
\hline
\end{tabular}

\begin{tabular}{|c|c|c|c|c|}
\hline Lymph node metastasi & & & & \\
\hline no & 17(37.0) & $30(37.5)$ & \multirow[t]{2}{*}{0.004} & \multirow[t]{2}{*}{0.952} \\
\hline yes & $29(63.0)$ & $50(62.5)$ & & \\
\hline \multicolumn{5}{|l|}{ Invasion } \\
\hline no & 16(34.8) & $31(38.8)$ & \multirow[t]{2}{*}{0.197} & \multirow[t]{2}{*}{0.658} \\
\hline yes & $30(62.5)$ & $49(61.3)$ & & \\
\hline \multicolumn{5}{|l|}{ Surgical } \\
\hline radical & $14(30.4)$ & $26(32.5)$ & \multirow[t]{3}{*}{0.215} & \multirow[t]{3}{*}{0.898} \\
\hline palliative & 18(39.1) & $28(35.0)$ & & \\
\hline biopsy & $14(30.4)$ & $26(32.5)$ & & \\
\hline average survival time & $10.07(4$ to 25$)$ & $10.34(3$ to 27$)$ & 0.014 & 0.906 \\
\hline \multicolumn{5}{|l|}{$\mathrm{CCT} 2$} \\
\hline- & $23(50.0)$ & $31(46.2)$ & \multirow[t]{2}{*}{0.165} & \multirow[t]{2}{*}{0.685} \\
\hline+ & $23(50.0)$ & 49(53.8) & & \\
\hline \multicolumn{5}{|l|}{ PDIA3 } \\
\hline- & $20(43.5)$ & $35(43.7)$ & \multirow[t]{2}{*}{0.001} & \multirow[t]{2}{*}{0.976} \\
\hline+ & $26(56.5)$ & $45(56.3)$ & & \\
\hline
\end{tabular}




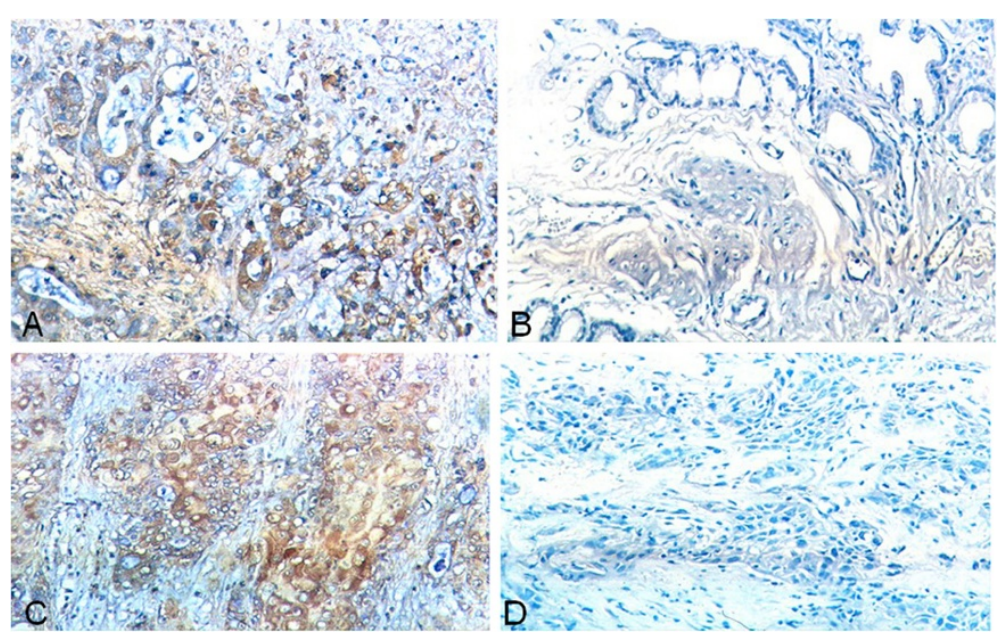

Figure 1 Expression of CCT2 and PDIA3 in gallbladder SC/ASC by IHC staining using EnVision system. (A) CCT2 positive expression in poorly-differentiated gallbladder ASC. (B) CCT2 negative expression in well-differentiated gallbladder ASC. (C) PDIA3 positive expression in poorly-differentiated gallbladder SC. (D) PDIA3 negative expression in moderately-differentiated gallbladder SC. Original magnification ×200.

gallbladder cancer registered in the same hospitals during the same period. For comparison, we also collected tissue samples from 80 patients with gallbladder AC from these hospitals during the period from January 2000 to December 2009. The study was approved by the Ethics Committee of Human Study of Central South University.

Among the $80 \mathrm{AC}$ patients, 26 patients were male and 54 patients were female, with a median age of $53.8 \pm 9.9$ (from 33 to 80 ) years. The pathological type (carcinoma differentiation) included 27 cases with well-differentiated carcinoma, 25 with moderately-differentiated carcinoma, and 28 with poorly-differentiated carcinoma. Fifty $(62.5 \%)$ patients had tumors $\leq 3 \mathrm{~cm}$ in diameter, and 30 (37.5\%) had tumors $>3 \mathrm{~cm}$. Gallstones were identified as a companion factor in 38 patients (47.5\%). Forty nine patients $(61.3 \%)$ had their tumor with adjacent tissue invasion, and 50 patients (62.5\%) had their tumor with regional lymph node metastasis. Staging analysis revealed that 8 cases were TNM stage I, 13 were stage II, 38 were stage III, and 21 were stage IV. 26 patients (32.5\%) underwent radical resections, 28 patients $(35.0 \%)$ underwent palliative resections, and 26 patients (32.5\%) underwent biopsies without complete tumor removal.

Among the $80 \mathrm{AC}$ patients, 26 patients were male and 54 patients were female, with a median age of $53.8 \pm 9.9$ (from 33 to 80 ) years. The pathological type (carcinoma differentiation) included 27 cases with well-differentiated carcinoma, 25 with moderately-differentiated carcinoma,

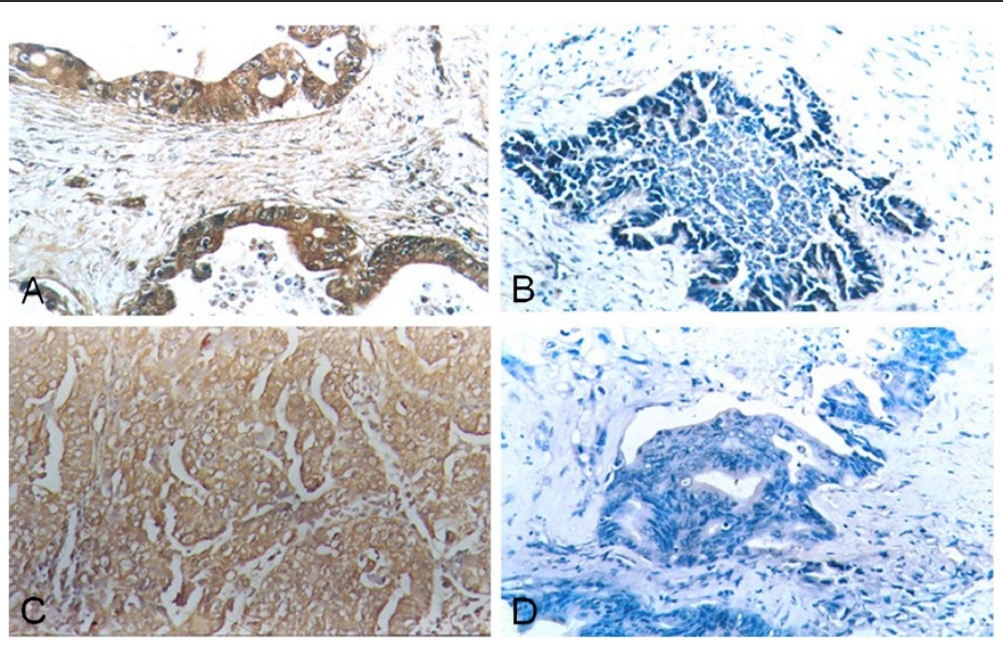

Figure 2 Expression of CCT2 and PDIA3 in gallbladder AC by IHC using EnVision system. (A) CCT2 positive expression in poorly-differentiated gallbladder AC. (B) CCT2 negative expression in well-differentiated gallbladder AC. (C) PDIA3 positive expression in poorly-differentiated gallbladder AC. (D) PDIA3 negative expression in well-differentiated gallbladder AC. Original magnification $\times 200$. 
and 28 with poorly-differentiated carcinoma. Fifty $(62.5 \%)$ patients had tumors $\leq 3 \mathrm{~cm}$ in diameter, and 30 (37.5\%) had tumors $>3 \mathrm{~cm}$. Gallstones were identified as a companion factor in 38 patients (47.5\%). Forty nine patients (61.3\%) had their tumor with adjacent tissue invasion, and 50 patients $(62.5 \%)$ had their tumor with regional lymph node metastasis. Staging analysis revealed that 8 cases were TNM stage I, 13 were stage II, 38 were stage III, and 21 were stage IV. 26 patients (32.5\%) underwent radical resections, 28 patients $(35.0 \%)$ underwent palliative resections, and 26 patients (32.5\%) underwent biopsies without complete tumor removal.
The 46 patients with SC/ASC and 80 patients with $\mathrm{AC}$ were followed for two years after surgery through mail and phone calls. Among the 46 SC/ASC patients, 33 patients survived for < one year after surgery and 13 patients survived for $\geq$ one year, of whom only 4 survived for more than two years. Average survival time for the SC/ASC patients was $10.07 \pm 0.78$ months. Of the $80 \mathrm{AC}$ patients, 57 patients survived for < one year after surgery and 23 patients survived for $\geq$ one year, of whom only 9 survived for more than two years. Average survival time for AC patients was $10.34 \pm 0.63$ months.

Table 2 The relationship between CCT2 and PDIA3 expression and clinicopathological features of gallbladder SC/ASC

\begin{tabular}{|c|c|c|c|c|c|c|c|}
\hline \multirow{2}{*}{$\begin{array}{l}\text { Clinicalpathological } \\
\text { features }\end{array}$} & \multirow[t]{2}{*}{ Case number } & \multicolumn{3}{|c|}{ CCT2 } & \multicolumn{3}{|c|}{ PDIA3 } \\
\hline & & Positive number (\%) & $\chi^{2}$ & $P$ & Positive number (\%) & $\chi^{2}$ & $P$ \\
\hline \multicolumn{8}{|l|}{ Gender } \\
\hline male & 19 & $7(36.8)$ & 2.242 & 0.134 & $12(63.2)$ & 0.580 & 0.446 \\
\hline female & 27 & $16(59.3)$ & & & $14(51.9)$ & & \\
\hline \multicolumn{8}{|l|}{ Age (years) } \\
\hline$\leq 45$ & 3 & $1(33.3)$ & 0.357 & 0.550 & $1(33.3)$ & 0.702 & 0.402 \\
\hline$>45$ & 43 & $22(51.2)$ & & & $25(58.1)$ & & \\
\hline \multicolumn{8}{|l|}{ Pathological types } \\
\hline SC & 26 & $14(53.8)$ & 0.354 & 0.552 & 18(69.2) & 3.930 & 0.047 \\
\hline ASC & 20 & $9(45.0)$ & & & $8(40.0)$ & & \\
\hline \multicolumn{8}{|l|}{ Degree of differentiation ${ }^{a}$} \\
\hline well-differentiated & 16 & $8(50.0)$ & 3.333 & 0.189 & $8(50.0)$ & 5.940 & 0.051 \\
\hline moderately-differentiated & 24 & $10(41.7)$ & & & $12(50.0)$ & & \\
\hline poorly-differentiated & 6 & $5(83.3)$ & & & $6(100.0)$ & & \\
\hline \multicolumn{8}{|c|}{ Tumor maximum diameter $(\mathrm{cm})$} \\
\hline$\leq 3 \mathrm{~cm}$ & 20 & $6(30.0)$ & 5.121 & 0.020 & $9(45.0)$ & 1.911 & 0.167 \\
\hline$>3 \mathrm{~cm}$ & 26 & $17(65.4)$ & & & $17(65.4)$ & & \\
\hline \multicolumn{8}{|l|}{ Gallbladder stones } \\
\hline no & 18 & 10(55.6) & 0.365 & 0.546 & $12(66.7)$ & 0.351 & 0.554 \\
\hline yes & 28 & $13(46.4)$ & & & $14(50.0)$ & & \\
\hline \multicolumn{8}{|l|}{ TNM stage } \\
\hline $1+\|$ & 12 & $3(25.0)$ & & & $5(41.7)$ & & \\
\hline III & 20 & $8(40.0)$ & 10.943 & 0.005 & $9(45.0)$ & 7.013 & 0.028 \\
\hline IV & 14 & $12(85.7)$ & & & $12(85.7)$ & & \\
\hline \multicolumn{8}{|l|}{ Lymph node metastasis } \\
\hline no & 17 & $5(29.4)$ & 4.572 & 0.033 & $6(35.5)$ & 4.945 & 0.026 \\
\hline yes & 29 & $18(62.1)$ & & & $20(69.0)$ & & \\
\hline \multicolumn{8}{|l|}{ Invasion } \\
\hline no & 16 & $5(31.3)$ & 3.450 & 0.063 & $5(31.3)$ & 6.376 & 0.012 \\
\hline yes & 30 & $18(60.0)$ & & & $21(70.0)$ & & \\
\hline \multicolumn{8}{|l|}{ Surgical } \\
\hline radical & 14 & $4(28.6)$ & 5.143 & 0.076 & $6(42.8)$ & 6.987 & 0.030 \\
\hline palliative & 18 & $9(50.0)$ & & & $8(44.4)$ & & \\
\hline biopsy & 14 & $10(71.4)$ & & & $12(85.7)$ & & \\
\hline
\end{tabular}

${ }^{a}$ Comparison between well-differentiated and moderately-differentiated SC/ ASC: $P_{\mathrm{CCT2}}=0.333 ; P_{\mathrm{PDIA} 3}=0.051 ;$ Comparison between moderately-differentiated and poorly-differentiated SC/ ASC: $P_{\mathrm{CCT} 2}=0.169 ; P_{\mathrm{PDIA} 3}=0.057$. 


\section{Specimen processing and immunohistochemistry (IHC) staining}

Surgically obtained specimens were fixed with $4 \%$ formaldehyde for 24 hours and then embedded in paraffin. The paraffin-embedded tissues were sectioned at $4 \mu \mathrm{m}$ thickness for immunostaining with CCT2 and PDIA3 antibodies using peroxidase-based EnVision ${ }^{\text {Tw }}$ Detection kit (Dako Laboratories, Carpinteria, CA, USA). Rabbit anti-CCT2 and rabbit anti-PDIA3 antibodies were purchased from Abgent Company (San Diego,, USA). The percentage of positive cells (brown cytoplasmic and/or nuclear staining) was calculated from 400 cells in 10 randomly selected fields. Cases with $\geq 25 \%$ positive cells were considered positive while cases with $<25 \%$ positive cells were considered negative [27-29]. For a positive control, a biopsy with positive expression of CCT2 and PDIA3 from Beijing Zhongshan Biotechnology Company (Beijing, China) was used, and for a negative control the primary antibody was replaced by $5 \%$ FBS for the staining.

\section{Statistical methods}

Data were analyzed using the SPSS13.0 statistical package from SPSS Inc (Chicago, USA).. The correlation between the expression of CCT2 or PDIA3 with the histological or clinical factors was analyzed using Chi square $\left(x^{2}\right)$ or Fisher's exact test. Univariate survival analysis was performed using the Kaplan-Meier method and log-rank

Table 3 The relationship between CCT2 and PDIA3 expression and clinicopathological features of gallbladder AC

\begin{tabular}{|c|c|c|c|c|c|c|c|}
\hline \multirow{2}{*}{$\begin{array}{l}\text { Clinical and pathological } \\
\text { features }\end{array}$} & \multirow[t]{2}{*}{ Case number } & \multicolumn{3}{|c|}{$\mathrm{CCT} 2$} & \multicolumn{3}{|c|}{ PDIA3 } \\
\hline & & Positive number (\%) & $\chi^{2}$ & $P$ & Positive number (\%) & $\chi^{2}$ & $P$ \\
\hline \multicolumn{8}{|l|}{ Gender } \\
\hline male & 26 & $14(53.8)$ & 0.000 & 0.990 & $14(53.8)$ & 0.090 & 0.764 \\
\hline female & 54 & $29(53.7)$ & & & $31(57.4)$ & & \\
\hline \multicolumn{8}{|l|}{$\leq 45$} \\
\hline$>45$ & 16 & $5(31.3)$ & 4.073 & 0.044 & $7(43.8)$ & 1.270 & 0.260 \\
\hline Degree of differentiation ${ }^{a}$ & 64 & $38(59.4)$ & & & $38(59.4)$ & & \\
\hline \multicolumn{8}{|l|}{ well-differentiated } \\
\hline moderately-Differentiated & 27 & 10(37.0) & 5.326 & 0.070 & $12(44.4)$ & 11.840 & 0.000 \\
\hline poorly-differentiated & 25 & 14(56.0) & & & $10(40.0)$ & & \\
\hline Tumor maximum diameter $(\mathrm{cm})$ & 28 & 19(67.9) & & & $23(82.1)$ & & \\
\hline \multicolumn{8}{|l|}{$\leq 3 \mathrm{~cm}$} \\
\hline$>3 \mathrm{~cm}$ & 50 & $22(44.0)$ & 5.099 & 0.024 & $23(46.0)$ & 5.692 & 0.017 \\
\hline Gallbladder stones & 30 & $21(70.0)$ & & & $22(73.3)$ & & \\
\hline \multicolumn{8}{|l|}{ no } \\
\hline yes & 42 & 19(45.2) & 2.577 & 0.108 & $25(59.5)$ & 0.343 & 0.558 \\
\hline TNM stage & 38 & $24(63.2)$ & & & $20(52.6)$ & & \\
\hline \multicolumn{8}{|l|}{$1+\|$} \\
\hline III & 21 & $6(28.6)$ & & & $7(33.3)$ & & \\
\hline IV & 38 & $20(52.6)$ & 11.625 & 0.003 & $20(52.6)$ & 12.092 & 0.002 \\
\hline Lymph node metastasis & 21 & $17(81.0)$ & & & $18(85.7)$ & & \\
\hline \multicolumn{8}{|l|}{ no } \\
\hline yes & 30 & 10(33.3) & 8.049 & 0.004 & $12(40.0)$ & 5.150 & 0.020 \\
\hline Invasion & 50 & $33(66.0)$ & & & $33(66.0)$ & & \\
\hline \multicolumn{8}{|l|}{ no } \\
\hline yes & 31 & $11(35.5)$ & 6.793 & 0.009 & $14(45.2)$ & 2.529 & 0.112 \\
\hline Surgical & 49 & $32(65.3)$ & & & $31(63.3)$ & & \\
\hline \multicolumn{8}{|l|}{ radical } \\
\hline palliative & 26 & $8(30.8)$ & 11.140 & 0.004 & $10(38.5)$ & 7.940 & 0.019 \\
\hline biopsy & 28 & $15(53.6)$ & & & 15(53.6) & & \\
\hline$\leq 45$ & 26 & $20(76.9)$ & & & $20(76.9)$ & & \\
\hline
\end{tabular}

${ }^{a}$ Comparison between well-differentiated and poorly-differentiated adenocarcinoma: $X^{2}{ }_{\text {ccT2 }}=5.24, P=0.022 ; X^{2}$ PDIA3 $=8.44, P=0.004$; Comparison between moderately-differentiated and poorly-differentiated adenocarcinoma: $x^{2}{ }_{\text {cCT2 }}=0.79, P=0.374 ; X^{2}$ PDIA3 $=9.98, P=0.002$. 
test. Cox proportional hazards regression model and Wald's test were used for multivariate survival analysis and for determining the $95 \%$ confidence intervals. $P$ values $<0.05$ were considered to be statistically significant.

Table 4 Relationship between CCT2 and PDIA3 expression and clinicopathological characteristics and average survival of gallbladder SC/ASC patients

\begin{tabular}{|c|c|c|c|c|}
\hline $\begin{array}{c}\text { Clinicopathological } \\
\text { features }\end{array}$ & $\begin{array}{c}\text { Case } \\
\text { number }\end{array}$ & $\begin{array}{l}\text { Average survival } \\
\text { (months) }\end{array}$ & $\chi^{2}$ & $P$ \\
\hline \multicolumn{5}{|l|}{ Gender } \\
\hline male & 19 & $10.74(6$ to 24$)$ & 0.767 & 0.381 \\
\hline female & 27 & $9.85(4$ to 24$)$ & & \\
\hline \multicolumn{5}{|l|}{ Age (years) } \\
\hline$\leq 45$ & 3 & 15.67(8 to 24$)$ & 2.023 & 0.155 \\
\hline$>45$ & 43 & $9.84(4$ to 24$)$ & & \\
\hline \multicolumn{5}{|l|}{ Pathological types } \\
\hline SC & 26 & $10.19(4$ to 24$)$ & 0.223 & 0.637 \\
\hline ASC & 20 & $10.25(4$ to 24$)$ & & \\
\hline \multicolumn{5}{|l|}{ Degree of differentiation $^{a}$} \\
\hline well-differentiated & 16 & 7.04(4 to 11$)$ & & \\
\hline moderately-Differentiated & 24 & $8.92(4$ to 18$)$ & 19.125 & 0.000 \\
\hline poorly-differentiated & 6 & $5.83(4$ to 9$)$ & & \\
\hline \multicolumn{5}{|l|}{$\begin{array}{l}\text { Tumor maximum diameter } \\
\qquad(\mathrm{cm})\end{array}$} \\
\hline$\leq 3 \mathrm{~cm}$ & 20 & $14.35(7$ to 24$)$ & 31.337 & 0.620 \\
\hline$>3 \mathrm{~cm}$ & 26 & 7.04(4 to 11$)$ & & \\
\hline \multicolumn{5}{|l|}{ Gallbladder stones } \\
\hline no & 18 & $8.22(4$ to 12$)$ & 3.730 & 0.053 \\
\hline yes & 28 & $11.50(4$ to 24$)$ & & \\
\hline \multicolumn{5}{|l|}{ TNM stage } \\
\hline $1+\|$ & 12 & $17.00(9$ to 24$)$ & & \\
\hline III & 20 & $9.20(7$ to 15$)$ & 51.139 & 0.000 \\
\hline IV & 14 & $5.86(4$ to 8$)$ & & \\
\hline \multicolumn{5}{|l|}{ Lymph node metastasis } \\
\hline no & 17 & $14.24(4$ to 24$)$ & 16.219 & 0.000 \\
\hline yes & 29 & $7.86(4$ to 15$)$ & & \\
\hline \multicolumn{5}{|l|}{ Invasion } \\
\hline no & 16 & $15.75(9$ to 24$)$ & 32.271 & 0.000 \\
\hline yes & 30 & $7.27(4$ to 12$)$ & & \\
\hline \multicolumn{5}{|l|}{ Surgical } \\
\hline radical & & 16.64(10 to 24$)$ & & \\
\hline palliative & & $8.50(6$ to 12$)$ & 50.165 & 0.000 \\
\hline biopsy & & $6.00(4$ to 8$)$ & & \\
\hline \multicolumn{5}{|l|}{$\mathrm{CCT} 2$} \\
\hline- & 23 & $12.96(6$ to 24$)$ & 14.073 & 0.000 \\
\hline+ & 33 & $7.48(4$ to 12$)$ & & \\
\hline \multicolumn{5}{|l|}{ PDIA3 } \\
\hline- & 20 & $12.75(6$ to 24$)$ & 7.011 & 0.008 \\
\hline+ & 26 & $8.27(4$ to 24$)$ & & \\
\hline
\end{tabular}

\section{Results}

Clinicopathological features of SC/ASC and AC

As shown in Table 1, GBC was diagnosed more frequently in older patients ( $>45$ years) than in those young patients ( $\leq 45$ years), and this was true for both SC/ASC (93.5\%) and $\mathrm{AC}(80 \%)$. However, tumors with poor differentiation were more frequently identified in $\mathrm{AC}$ patients than in SC/ASC patients $(P<0.05)$ (Table 1$)$. On the other hand, the percentage of patients with tumor mass $>3 \mathrm{~cm}$ was higher in SC/ACS patients (56.5\%) than in AC patients (37.5) $(P<0.05)$. There were no significant differences in gender, presence of gallstones, TNM stage, lymph node metastases, adjacent tissue invasion, surgical procedure, or

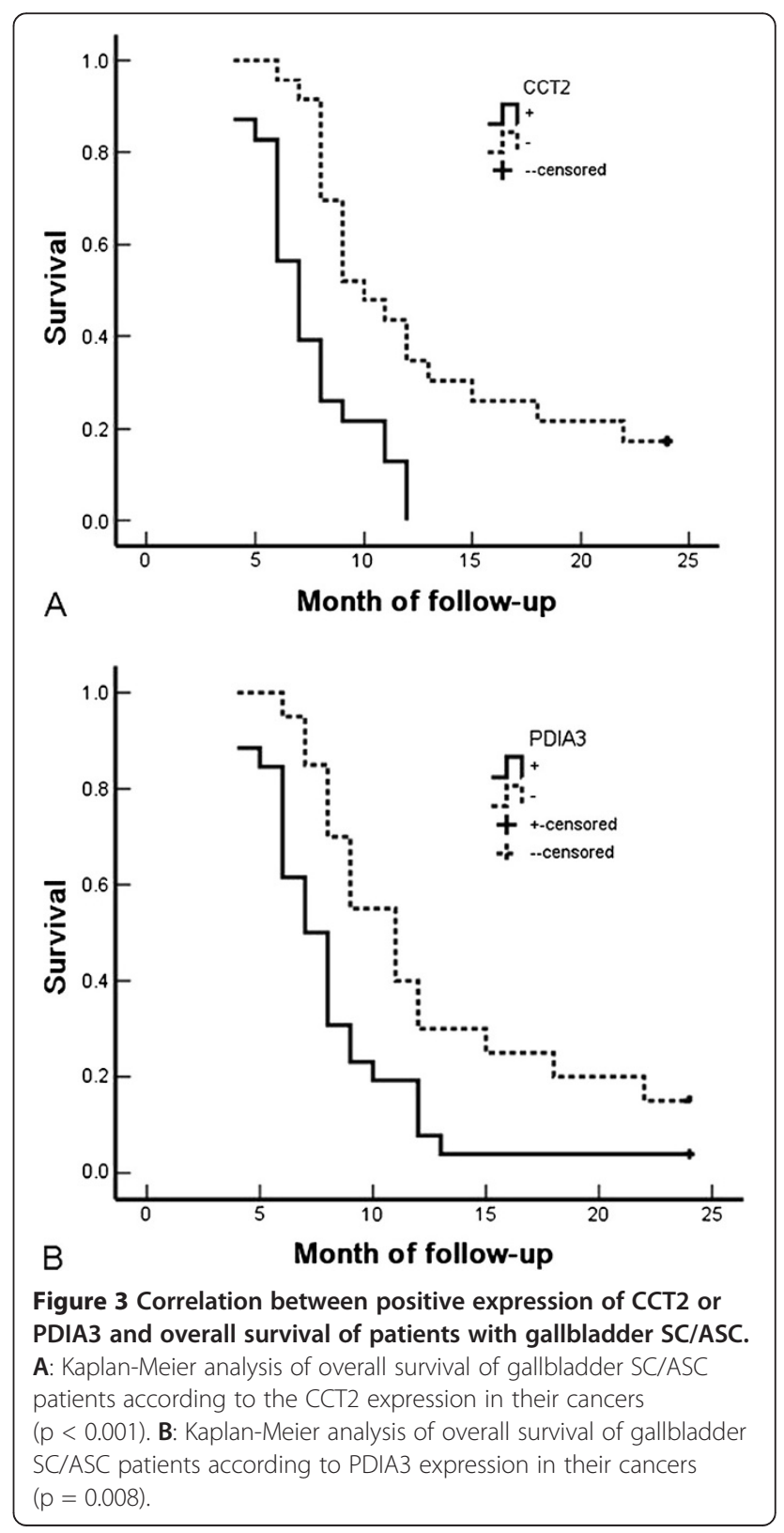


average survival time between patients with SC/ASC and AC $(P>0.05)$.

\section{Expression of CCT2 and PDIA3 in SC/ASC and AC}

The expression of CCT2 and PDIA3 by immunohistochemical (IHC) staining was detected predominately in the cytoplasm and occasionally in the nucleus (Figures 1 and 2). Among $46 \mathrm{SC} / \mathrm{ASC}$ tissue samples, 23 (50\%) samples showed CCT2 positive expression and 26 (56.5\%) samples had PDIA3 positive expression (Table 1). In the $80 \mathrm{AC}$ specimens, we found that $43(53.8 \%)$ samples expressed CCT2 and 45 (56.3\%) expressed PDIA3 (Table 1). There were no differences in the expression patterns of CCT2 or PDIA3 between the different GBC subtypes $(P>0.05)$.

\section{Relationship between CCT2 and PDIA3 expression and} clinicopathological features of SC/ASC and AC subtypes As shown in Table 2, the expression of CCT2 in tissue samples of SC/ASC significantly correlated with tumor size, TNM stage, and lymph node metastasis status. The percentage of tumor samples with CCT2 expression detected by IHC was significantly different between large tumors and small tumors. 65.4\% of large tumors (tumor $>3 \mathrm{~cm}$ ) had CCT2 expression whereas only $30 \%$ of small tumors (tumor $\leq 3 \mathrm{~cm}$ ) showed CCT2 expression. Moreover, $85.7 \%$ of stage IV tumor samples expressed CCT2, which was significantly higher than that of stage III (40\%) and stage I+II (20\%) tumor samples. In addition, CCT2 expression was detected more frequently in tumors with lymph node metastasis $(62.1 \%)$ than those without lymph node metastasis (29.4\%) (Table 2, $P=0.03)$. There was no significant correlation between CCT2 expression and patient gender, age, histopathological types, gallstones, adjacent tissue invasion, or surgical procedure $(P>0.05)$.

In contrast to CCT2 expression, which showed no significant differences between AC and ASC, PDIA3 was expressed more frequently in SC than ASC (Table 2, $P=0.047$ ). Moreover, a higher expression of PDIA3 significantly correlated with higher TNM stage, adjacent tissue invasion, and lymph node metastasis (Table 2, $P<0.05$ ).

Similar findings were observed in the AC subtype of GBC. As shown in Table 3, the poorer the differentiation of tumors, the higher the percentage of tumors with CCT2 expression. In addition, the higher the TNM stage of $\mathrm{AC}$, the higher the percentage of tumors with CCT2 expression (Table 3, $P<0.05$ ). Furthermore, we observed a significant correlation between the expression of CCT2 and tumor size, invasion status, and lymph node metastasis of AC as well as patient age (Table $3, P<0.05$ ).

In contrast to the expression of PDIA3 in SC/ASC, we found that the expression of PDIA3 in AC significantly correlated not only with large tumor size, higher TNM stage, and lymph node metastasis, but also with poor differentiation (Table 3, $P<0.05$ ). However, no correlation between PDIA3 expression and adjacent tissue invasion was observed in AC analyzed (Table 3, $P>0.05$ ).

\section{Impact of CCT2 and PDIA3 expression on overall survival of SC/ASC and AC patients}

To further understand the importance of CCT2 and PDIA3 expression for $\mathrm{SC} / \mathrm{ASC}$ and $\mathrm{AC}$ of $\mathrm{GBC}$, we analyzed the survival data of all $46 \mathrm{SC} / \mathrm{ASC}$ and $80 \mathrm{AC}$ patients after two years of following-up. Patients surviving longer than two years were censored from the statistical analysis. We chose two years as the mark point for our survival data analysis because a majority of the patients died within two years of surgery.

We found a significant correlation between CCT2 and PDIA3 expression and the survival rate of SC/ASC patients. The survival time of patients with CCT2 and PDIA3 expression in their tumors was significantly shorter than that of patients without CCT2 and PDIA3 expression in their tumors $(P<0.001$ and $P=0.008$ for

Table 5 Multivariate Cox regression analysis of survival rate in SC/ASC patients

\begin{tabular}{|c|c|c|c|c|c|c|c|c|}
\hline \multirow[t]{2}{*}{ Group } & \multirow[t]{2}{*}{ Factors } & \multirow[t]{2}{*}{ RC } & \multirow[t]{2}{*}{ SE } & \multirow[t]{2}{*}{ Wald } & \multirow[t]{2}{*}{ RR } & \multirow[t]{2}{*}{$P$} & \multicolumn{2}{|c|}{$95 \%$ confidence interval } \\
\hline & & & & & & & Lower limit & Upper limit \\
\hline Pathologic type & SC/ASC & .028 & .379 & .005 & 1.028 & .941 & .489 & 2.162 \\
\hline Degree of differentiation & well-/moderately-/poorly-differentiated & .856 & .357 & 5.749 & 2.354 & .016 & 1.169 & 4.738 \\
\hline Tumor diameter $(\mathrm{cm})$ & $\leq 3 \mathrm{~cm} />3 \mathrm{~cm}$ & 2.225 & .863 & 6.647 & 9.253 & .010 & 1.705 & 50.223 \\
\hline Gallbladder stones & no/yes & .669 & .405 & 2.729 & 1.952 & .099 & .883 & 4.318 \\
\hline TNM stage & $I+I I / I I I I V$ & 1.231 & .457 & 7.256 & 3.425 & .007 & 1.398 & 8.387 \\
\hline Lymph node metastasis & no/yes & 1.645 & .578 & 8.100 & 5.181 & .004 & 1.669 & 16.085 \\
\hline Adjacent invasion & no/yes & 2.498 & .796 & 9.848 & 12.158 & .002 & 2.554 & 57.868 \\
\hline Surgical approach & radical/palliative/biopsy & 2.762 & .822 & 11.290 & 15.831 & .001 & 3.161 & 79.291 \\
\hline $\mathrm{CCT} 2$ & $-/+$ & 1.001 & .547 & 3.349 & 2.721 & .067 & .931 & 7.950 \\
\hline PDIA3 & $-/+$ & 0.889 & .418 & 4.523 & 2.433 & .033 & 1.072 & 5.519 \\
\hline
\end{tabular}

$R C$ regression coefficient, $S E$ standard error, Wald Wald $X^{2}, R R$ relative risk. 
CCT2 and PDIA3, respectively) (Table 4 and Figure 3). In addition, Kaplan-Meier survival analysis of SC/ASC patients revealed that the average survival time was highly correlated with histological differentiation, tumor size, TNM stage, lymph node metastasis, and adjacent tissue invasion (Table $4, P<0.005$ ). Cox multivariate analysis indicated that poor differentiation, tumor size $>3 \mathrm{~cm}$, TNM stage III or IV, lymph node metastases, adjacent tissue invasion, no resection, and CCT2 and PDIA3 positive expression all negatively correlated with postsurgery survival time, and positively correlated with patient mortality rate (Table $5, P<0.05$ ). In addition, CCT2 positivity was found to be an independent prognostic risk factor for SC/ASC (Table 5, $P=0.033$ ).

Similar to the findings in SC/ASC, we also found that the expression of CCT2 and PDIA3 significantly correlated with the shorter survival time of AC patients $(P<0.001$ and $P=0.001$ for CCT2 and PDIA3, respectively, in Table 6, and Figure 4). In addition, poor differentiation, tumor size $>3 \mathrm{~cm}$, TNM stage III or IV, lymph node metastases, adjacent tissue invasion, no resection, and positive expression of CCT2 and/or PDIA3 were all negatively correlated with post-surgery survival rate, and positively correlated with patient mortality rate (Table 7, $P<0.05$ ). In contrast to that in SC/ASC, both CCT2 expression and PDIA3 expression were independent prognostic risk factors for AC (Table 7, $P=0.04$ and $P=0.014$ for CCT2 and PDIA3, respectively).

\section{Discussion}

In this study, we analyzed the expression of CCT2 and PDIA3 by IHC staining in $46 \mathrm{SC}$ /ASC samples as well as in $80 \mathrm{AC}$ samples, and found that both CCT2 expression and PDIA3 expression were significantly correlated with tumor progression and shorter survival time for patients with SC/ASC and AC.

For the first time, we found that positive CCT2 expression in both SC/ASC and AC subtypes was significantly associated with clinicopathological features, including large tumor size, high TNM stage, and lymph node metastasis. Moreover, positive expression of CCT2 in $\mathrm{AC}$ also correlated with poor differentiation and adjacent tissue invasion. These results, taken together, suggest an important role for CCT2 in GBC progression. Given the critical role of CCT2 in assisting the folding of actin, tubulin, and other cytosolic proteins [14,15], we assumed that the increased CCT2 expression in GBC cells might be critical for these cells to meet the increased levels of protein folding required during fast growth. In line with this hypothesis, overall survival analysis showed that the survival time of patients with positive CCT2 expression was significantly shorter than that of patients with CCT2 negative expression. Moreover, CCT2 is identified as an independent prognostic biomarker for both SC/ASC and
Table 6 Relationship between CCT2 and PDIA3 expression and clinicopathological characteristics and average survival of gallbladder AC patients

\begin{tabular}{|c|c|c|c|c|}
\hline $\begin{array}{l}\text { Clinicopathological } \\
\text { features }\end{array}$ & $\begin{array}{c}\text { Case } \\
\text { number }\end{array}$ & $\begin{array}{c}\text { Average survival } \\
\text { (months) }\end{array}$ & $\chi^{2}$ & $P$ \\
\hline \multicolumn{5}{|l|}{ Gender } \\
\hline male & 26 & $9.58(3$ to 24$)$ & 2.567 & 0.109 \\
\hline female & 54 & $11.30(3$ to 24$)$ & & \\
\hline \multicolumn{5}{|l|}{ Age (years) } \\
\hline$\leq 45$ & 16 & $10.81(4$ to 24$)$ & 0.003 & 0.956 \\
\hline$>45$ & 64 & $10.72(3$ to 24$)$ & & \\
\hline \multicolumn{5}{|l|}{ Degree of differentiation $^{a}$} \\
\hline well-differentiated & 27 & $15.07(5$ to 24$)$ & & \\
\hline moderately-differentiated & 25 & $10.60(4$ to 24$)$ & 32.501 & 0.000 \\
\hline poorly-differentiated & 28 & $6.68(3$ to 14$)$ & & \\
\hline \multicolumn{5}{|l|}{$\begin{array}{l}\text { Tumor maximum } \\
\text { diameter }(\mathrm{cm})\end{array}$} \\
\hline$\leq 3 \mathrm{~cm}$ & 50 & $13.70(6$ to 24$)$ & 68.283 & 0.000 \\
\hline$>3 \mathrm{~cm}$ & 30 & $5.80(3$ to 10$)$ & & \\
\hline \multicolumn{5}{|l|}{ Gallbladder stones } \\
\hline no & 42 & 10.19(3 to 24$)$ & 0.246 & 0.620 \\
\hline yes & 38 & $11.34(4$ to 24$)$ & & \\
\hline \multicolumn{5}{|l|}{ TNM stage } \\
\hline $1+\|$ & 21 & $18.96(5$ to 24$)$ & & \\
\hline III & 38 & $9.29(6$ to 15$)$ & 105.825 & 0.000 \\
\hline IV & 21 & $5.14(3$ to 7$)$ & & \\
\hline \multicolumn{5}{|l|}{ Lymph node metastasis } \\
\hline no & 30 & $16.27(4$ to 24$)$ & 42.372 & 0.000 \\
\hline yes & 50 & $7.42(3$ to 14$)$ & & \\
\hline \multicolumn{5}{|l|}{ Invasion } \\
\hline no & 31 & $16.68(7$ to 24$)$ & 55.535 & 0.000 \\
\hline yes & 49 & $6.98(3$ to 11$)$ & & \\
\hline \multicolumn{5}{|l|}{ Surgical } \\
\hline radical & 26 & $18.31(10$ to 24$)$ & & \\
\hline palliative & 28 & $8.64(6$ to 11$)$ & 113.141 & 0.000 \\
\hline biopsy & 26 & $5.42(3$ to 9$)$ & & \\
\hline \multicolumn{5}{|l|}{$\mathrm{CCT} 2$} \\
\hline- & 37 & $13.78(6$ to 24$)$ & 17.876 & 0.000 \\
\hline+ & 43 & $8.12(3$ to 24$)$ & & \\
\hline \multicolumn{5}{|l|}{ PDIA3 } \\
\hline- & 35 & $13.46(5$ to 24$)$ & 11.604 & 0.001 \\
\hline+ & 45 & $8.62(3$ to 24$)$ & & \\
\hline
\end{tabular}

AC patients in our multivariate survival analysis. In addition to its up-regulation in GBC, CCT2 up-regulation has been reported in other human tumors and is related to drug-resistance of tumor cells [20]. Therefore, CCT2 in GBC may also contribute to chemotherapeutic resistance, which is important for the clinical treatment of GBC and warrants further study. 


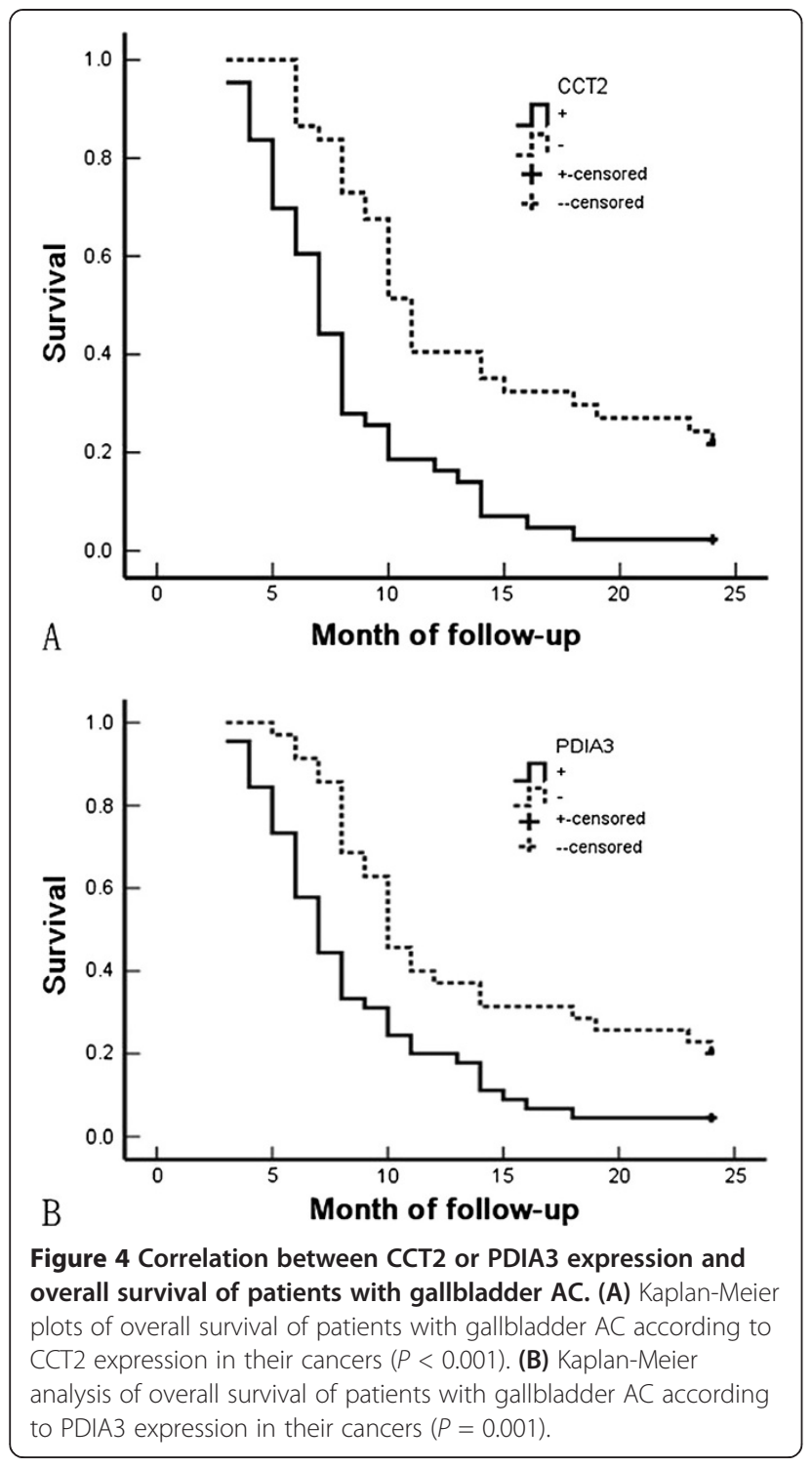

Table 7 Multivariate Cox regression analysis of survival rate in AC patients

\begin{tabular}{|c|c|c|c|c|c|c|c|c|}
\hline \multirow[t]{2}{*}{ Group } & \multirow[t]{2}{*}{ Factors } & \multirow[t]{2}{*}{$\mathrm{RC}$} & \multirow[t]{2}{*}{ SE } & \multirow[t]{2}{*}{ Wald } & \multirow[t]{2}{*}{ RR } & \multirow[t]{2}{*}{$P$} & \multicolumn{2}{|c|}{$95 \%$ confidence interval } \\
\hline & & & & & & & Lower limit & Upper limit \\
\hline Degree of differentiation & Well-/moderately-/poorly- differentiated & 1.040 & .497 & 4.379 & 2.829 & .036 & 1.068 & 7.494 \\
\hline Tumor diameter $(\mathrm{cm})$ & $\leq 3 \mathrm{~cm} />3 \mathrm{~cm}$ & 1.003 & .410 & 5.985 & 2.726 & .014 & 1.221 & 6.090 \\
\hline Gallbladder stones & no/yes & .077 & .246 & .098 & 1.080 & .754 & .667 & 1.749 \\
\hline TNM stage & $I+\| / I I / I V$ & 1.227 & .419 & 8.576 & 3.411 & .003 & 1.500 & 7.754 \\
\hline Lymph node metastasis & no/yes & 1.183 & .454 & 6.790 & 3.264 & .009 & 1.341 & 7.947 \\
\hline Adjacent invasion & no/yes & 1.021 & .507 & 4.055 & 2.776 & .044 & 1.028 & 7.499 \\
\hline Surgical approach & radical/palliative/biopsy & 1.849 & .424 & 19.017 & 6.353 & .000 & 2.768 & 14.586 \\
\hline CCT2 & $-1+$ & .853 & .296 & 8.305 & 2.347 & .004 & 1.314 & 4.192 \\
\hline PDIA3 & $-/+$ & .682 & .278 & 6.018 & 1.978 & .014 & 1.147 & 3.411 \\
\hline
\end{tabular}

$R C$ regression coefficient, $S E$ standard error, Wald Wald $\mathbf{X}^{2}, R R$ relative risk.
Up-regulation of PDIA3 expression is linked to cellular stress response [30]. PDIA3 is also connected to the apoptotic process and has an anti-apoptotic effect in the melanoma cells after induction of endoplasmatic reticulum stress [31]. Overexpression of PDIA3 has been reported in various tumors, including melanomas, cervical carcinoma, ovarian carcinoma, esophageal squamous cell carcinoma, and hepatocellular carcinoma, and is associated with tumor progression, metastasis and poor patient survival rate [22-24,32-35]. Consistent with these studies, we found that positive PDIA3 expression was significantly associated with higher TNM stage, surrounding tissue invasion and lymph node metastasis in both SC/ASC and AC subtypes of GBC. In addition, PDIA3 expression was correlated with poor differentiation and large tumor size in the $\mathrm{AC}$ subtype. Furthermore, positive PDIA3 expression was significantly related to the overall survival of patients with both SC/ASC and AC. Therefore, the expression level of PDIA3 in AC and SC/ASC reflected the progression and clinical behavior of gallbladder cancer and might be an important biomarker of poor prognosis. It should be noted that in some cancer types, down-regulation of PDIA3 is related to tumor progression. For example, a lack of PDIA3 expression has been correlated with increased tumor invasion and the advanced stage of gastric cancer, and has therefore been proposed as a good prognostic marker [36]. In addition, PDIA3 expression is downregulated in metastatic prostate cancer, suggesting that down regulation of PDIA3 might play a role in the late onset of prostate cancer progression [37]. Therefore, the expression of PDIA3 and its role in tumor progression seems to be tumor type specific.

Although there are differences in histopathological features and incidence between SC/ASC and AC subtypes of GBC, our study provided evidence that both SC/ASC and $\mathrm{AC}$ have common molecular features, that is, positive expression of CCT2 and PDIA3, and that the expression of CCT2 and PDIA3 in tumor cells correlates with tumor progression and poor prognosis. 


\section{Conclusion}

In conclusion, positive expression of CCT2 and PDIA3 are associated with large tumor size, high TMN stage, lymph node metastasis, adjacent tissue invasion, and poor prognosis of SC/ASC and AC. Expression of CCT2 and PDIA3 may reflect the progression and clinical behavior of GBC. CCT2 and PDIA3 could be important diagnostic and prognostic biomarkers for both the SC/ASC and $\mathrm{AC}$ subtypes of GBC.

\section{Abbreviations}

GBC: gallbladder cancer; AC: adenocarcinoma; SC/ASC: squamous cell carcinoma/adenosquamous carcinoma; CCT2: chaperonin containing TCP1, subunit 2; PDIA3: protein disulfide isomerase A3; AFP: alpha-fetoprotein; FBS: fetal bovine serum; IHC: immunohistochemistry.

\section{Competing interests}

The authors declare that there are no competing financial interests in this study.

\section{Authors' contributions}

$\mathrm{QZ}, \mathrm{YY}$ and ZLY designed the study, performed the sequence alignment, and drafted the manuscript. JHL performed the sequence alignment. LFL designed the study and performed the statistical analysis. GXZ and SLC conceived the study, participated in its design, and coordinated it, and helped to draft the manuscript. All authors have read and approved the final manuscript.

\section{Acknowledgements}

This work was supported by the Hunan Provincial Health Department research fund (project B2012-035).

\section{Author details}

'Department of Pathology, Third Xiangya Hospital, Central South University, Changsha, Hunan 410013, PR China. ${ }^{2}$ Research Laboratory of Hepatobiliary Diseases, Second Xiangya Hospital, Central South University, Changsha, Hunan 410011, PR China. ${ }^{3}$ Department of Pathology, Basic School of Medicine, Central South University, Changsha, Hunan 410078, PR China. ${ }^{4}$ Department of Hepatobiliary and Pancreatic Surgery, Hunan Provincial People's Hospital, Changsha, Hunan 410007, PR China. ${ }^{5}$ Department of Pathology, Loudi Central Hospital, Loudi, Hunan 417011, PR China. ${ }^{6}$ Department of Pathology, Hunan Provincial Tumor Hospital, Changsha, Hunan 410013, PR China.

Received: 30 January 2013 Accepted: 2 June 2013

Published: 19 June 2013

\section{References}

1. Hsing AW, Gao YT, Rashid A, et al: Gallstones and the risk of biliary tract cancer: a population-based study in China. British J Cancer 2007, 97:1577-1582.

2. Hawkins WG, DeMatteo RP, Jarnagin WR, et al: Jaundice predicts advanced disease and early mortality in patients with gallbladder cancer. Ann Surg Oncol 2004, 11:310-315.

3. Kim WS, Jang KT, Choi SH, et al: Clinicopathologic analysis of adenosquamous/squamous cell carcinoma of the gallbladder. J Surg Oncol 2011, 103:239-242.

4. Chan KM, Yu MC, Lee WC, et al: Adenosquamous/squamous cell carcinoma of gallbladder. J Surg Oncol 2007, 95:129-134

5. Mingoli A, Brachini G, Petroni R, et al: Squamous and adenosquamous cell carcinoma of carcinomas of the gallbladder. J Exp Clin Cancer Res 2005 24:143-150.

6. Kondo M, Dono K, Sakon M, et al: Adenosquamous carcinoma of the gallbladder. Hepatogastroenterology 2002, 49:1230-4

7. Oohashi Y, Shirai Y, Wakai T, et al: Adenosquamous carcinoma of the gallbladder warrants resection only if curative resection is feasible. Cancer 2002, 94:3000-3005.

8. Nishihara $K$, Nagai E, Izumi $Y$, et al: Adenosquamous carcinoma of the gallbladder: a clinicopathological, immunohistochemical and flow-cytometric study of twenty cases. Jpn J Cancer Res 1994, 85:389-399.
9. Kubota $H$, Hynes $G$, Willison $\mathrm{K}$ : The chaperonin containing $\mathrm{t}$-complex polypeptide 1 (TCP-1). Multisubunit machinery assisting in protein folding and assembly in the eukaryotic cytosol. Eur J Biochem 1995, 230:3-16.

10. Kubota $H$, Hynes $G$, Willison $K$ : The eighth Cct gene, Cctq, encoding the theta subunit of the cytosolic chaperonin containing TCP-1. Gene 1995, 154:231-236.

11. Dekker C, Stirling PC, McCormack EA, et al: The interaction network of the chaperonin CCT. EMBO J 2008, 27:1827-1839.

12. Amit M, Weisberg SJ, Nadler-Holly M, et al: Equivalent mutations in the eight subunits of the chaperonin CCT produce dramatically different cellular and gene expression phenotypes. J Mol Biol 2010, 401:532-543.

13. Grantham J, Brackley KI, Willison KR: Substantial CCT activity is required for cell cycle progression and cytoskeletal organization in mammalian cells. Exp Cell Res 2006, 312:2309-2324.

14. Cowan NJ, Lewis SA: Type II chaperonins, prefoldin and the tubulinspecific chaperones. Adv Prot Chem 2001, 59:73-104.

15. Frydman J: Folding of newly translated proteins in vivo: the role of molecular chaperones. Annu Rev Biochem 2001, 70:603-647.

16. Yokota S, Yamamoto Y, Shimizu K, et al: Increased expression of cytosolic chaperonin CCT in human hepatocellular and colonic carcinoma. Cell Stress Chaperones 2001, 6:345-350

17. Coghlin C, Carpenter B, Dundas SR, et al: Characterization and over-expression of chaperonin t-complex proteins in colorectal cancer. J Pathol 2006 210:351-357.

18. Qian-Lin Z, Ting-Feng W, Qi-Feng C, et al: Inhibition of cytosolic chaperonin $\mathrm{CCT \zeta}-1$ expression depletes proliferation of colorectal carcinoma in vitro. J Surg Oncol 2010, 102:419-423.

19. Malta-Vacas J, Nolasco S, Monteiro C, et al: Translation termination and protein folding pathway genes are not correlated in gastric cancer. Clin Chem Lab Med 2009, 47:427-431.

20. Lin YF, Tsai WP, Liu HG, et al: Intracellular beta-tubulin/chaperonin containing TCP1-beta complex serves as a novel chemotherapeutic target against drug-resistant tumors. Cancer Res 2009, 69:6879-6888.

21. Lindquist JA, Jensen ON, Mann M, et al: ER-60, a chaperone with thiol-dependent reductase activity involved in MHC class I assembly. EMBO J 1998, 17:2186-2195.

22. Brocke P, Garbi N, Momburg F, et al: HLA-DM, HLA-DO and tapasin: functional similarities and differences. Curr Opin Immunol 2002, 14:22-29.

23. Chay D, Cho H, Lim BJ, et al: ER-60 (PDIA3) is highly expressed in a newly established serous ovarian cancer cell line, YDOV-139. Int J Oncol 2010, 37:399-412.

24. Teramoto $R$, Minagawa $H$, Honda $M$, et al: Protein expression profile characteristic to hepatocellular carcinoma revealed by 2D-DIGE with supervised learning. Biochim Biophys Acta 2008, 1784:764-772.

25. Lwin ZM, Yip GW, Chew FT, et al: Downregulation of ER60 protease inhibits cellular proliferation by inducing $\mathrm{G} 1 / \mathrm{S}$ arrest in breast cancer cells in vitro. Anat Rec (Hoboken) 2012, 295:410-416.

26. Krynetskaia NF, Phadke MS, Jadhav SH, et al: Chromatin-associated proteins HMGB1/2 and PDIA3 trigger cellular response to chemotherapy-induced DNA damage. Mol Cancer Ther 2009, 8:864-872.

27. Sanada Y, Yoshida K, Ohara M, et al: Expression of orotate phosphoribosyltransferase in hepatobiliary ans pancreatic carcinoma. Pathol Oncol Res 2007, 13:105-113.

28. Chang HJ, Yoo BC, Kim SW, et al: Significances of PML and P53 protein as molecular prognostic markers of gallbladder carcinomas. Pathol Oncol Res 2007, 13:326-335.

29. Nemeth Z, Szasz AM, Somoracz AT, et al: Zonula occludin, and E-cadherin protein expression in biliary tract cancer. Pathol Oncol Res 2009, 15:533-539.

30. Ni M, Lee AS: ER chaperones in mammalian development and human diseases. FEBS Lett 2007, 581:3641-3651.

31. Corazzari M, Lovat PE, Armstrong $\mathrm{JL}$, et al: Targeting homeostatic mechanisms of endoplasmic reticulum stress to increase susceptibility of cancer cells to fenretinide-induced apoptosis: the role of stress proteins ERdj5 and ERp57. Br J Cancer 2007, 96:1062-1071.

32. Linge A, Kennedy S, O'Flynn D, et al: Differential expression of fourteen proteins between uveal melanoma from patients who subsequently developed distant metastases versus those who did not. Invest Ophthalmol Vis Sci 2012, 53:4634-4643.

33. Liao CJ, Wu TI, Huang YH, et al: Glucose-regulated protein 58 modulates cell invasiveness and serves as a prognostic marker for cervical cancer. Cancer Sci 2011, 102:2255-2263. 
34. Kashyap MK, Harsha HC, Renuse S, et al: SILAC-based quantitative proteomic approach to identify potential biomarkers from the esophageal squamous cell carcinoma secretome. Cancer Biol Ther 2010, 10:796-810.

35. Cicchillitti L, Di Michele M, Urbani A, et al: Comparative proteomic analysis of paclitaxel sensitive A2780 epithelial ovarian cancer cell line and its resistant counterpart A2780TC1 by 2D-DIGE: the role of ERp57. J Proteome Res 2009, 8:1902-1912.

36. Leys CM, Nomura S, LaFleur BJ, et al: Expression and prognostic significance of prothymosin-alpha and ERp57 in human gastric cancer. Surgery 2007, 141:41-50

37. Dhanasekaran SM, Barrette TR, Ghosh D, et al: Delineation of prognostic biomarkers in prostate cancer. Nature 2001, 412:822-826.

doi:10.1186/1477-7819-11-143

Cite this article as: Zou et al:: Clinicopathological features and CCT2 and PDIA2 expression in gallbladder squamous/adenosquamous carcinoma and gallbladder adenocarcinoma. World Journal of Surgical Oncology 2013 11:143.

\section{Submit your next manuscript to BioMed Central and take full advantage of:}

- Convenient online submission

- Thorough peer review

- No space constraints or color figure charges

- Immediate publication on acceptance

- Inclusion in PubMed, CAS, Scopus and Google Scholar

- Research which is freely available for redistribution 